\title{
Support workers in community mental health teams for older people: roles, boundaries, supervision and training.
}

\begin{abstract}
Aims: To explore the support worker functions in community mental health teams for older adults in relation to roles, boundaries, supervision and training.
\end{abstract}

Background: Support workers in community mental health teams provide important help to older people with complex mental and physical health needs in their own homes. Their numbers have grown substantially in recent years, but without professional registration there is concern that boundaries with qualified practitioners are insufficiently clear, and that they do not receive the support they require.

Design: Qualitative research using interview data and thematic framework analysis investigated support workers' and registered practitioners' perspectives on roles, boundaries, supervision and training.

Methods: Semi-structured face-to-face interviews were undertaken in 2011, with 42 members of nine teams spread across England, including support workers and community mental health nurses. Coding of transcribed audio-recordings and subsequent analysis was undertaken by four researchers.

Results: Support workers undertook diverse roles and had considerable autonomy over their duties. Participants agreed over what tasks support workers should not undertake, yet there was evidence of 'negotiated' boundaries and examples of these being breached. Lines of authority were complex, yet support workers were supported through open communication with the wider team. Training was problematic, with few courses tailored for support workers and efforts towards formal qualification hindered by low pay and time pressures. 
Conclusion: Local and national attention is needed to prevent 'drift' into activities that both support workers and registered practitioners consider outside their remit. Barriers to training and further qualification need to be addressed.

Keywords: Nursing, support workers, healthcare assistants, unlicensed assistive personnel, roles, supervision, training.

\section{SUMMARY STATEMENT}

\section{Why is this research or review needed?}

- Support workers provide important help to older people with mental health needs in their own home, but little is known about their role and remit.

- It is not clear if support worker roles complement, rather than substitute for, nursing skills; nor whether boundaries are clear.

- Furthermore, little is known about whether support workers in mental health services feel they are sufficiently supported, supervised and offered appropriate training.

\section{What are the key findings?}

- Support workers in this study undertook diverse roles, and whilst respondents were clear what tasks they should not be doing, there was otherwise much negotiation over what they should do.

- Sometimes support workers did work they considered outside their remit, or were not suitably supported. However, this risk was mitigated by good communication between them and the rest of the team.

- Training opportunities appeared either absent or unsuitable, and those seeking formal qualifications were stymied by low pay and time pressures.

\section{How should the findings be used to influence policy/practice/research/education?}


- Services should specify clear roles and boundaries to prevent 'role drift', but account for the skills and experiences individual support workers may bring.

- Both local providers and national professional bodies should address the barriers to training and skills acquisition if support workers are to be encouraged to further their development.

\section{INTRODUCTION}

Recent decades have seen a proliferation of healthcare roles undertaken by practitioners without professional registration. Although nomenclature varies, job titles commonly include terms such as 'associate', 'assistant/assistive', 'auxiliary', 'aide' ,'support', 'technician' and 'unlicensed' (International Council of Nurses 2000,World Health Organisation [WHO] 2007), whilst the term 'support workers' (adopted here) is increasingly used as a collective noun (Duffield et al. 2014). This expansion has fundamentally changed the skill-mix of the global care workforce, as governments have explored ways of meeting greater demands for nurses and allied health professionals from a chronic shortage in supply and budget (Buchan \& Dal Poz 2002, Dubois \& Singh 2009, Frenk et al. 2010, Fulton et al. 2011). In England, support workers comprise around a quarter of the National Health Service workforce, and their numbers continue to grow at a faster rate than their qualified counterparts (Health and Social Care Information Centre 2016), a trend mirrored in the United States, Australia and elsewhere (Duffield et al. 2014).

Support workers play a particularly important role in community care for people with severe and enduring mental health problems (Department of Health [DH] 2007). However, their work is not well specified, and the limited available guidance has a sparse evidence base, especially in respect to their activities with older adults. This paper reports the findings of a new exploratory study which sought to understand the role of support workers in nine community old age mental health providers in England. 


\section{Background}

Support workers have long been regarded as an essential component of the healthcare workforce, particularly in nursing where auxiliary workers were specified in the earliest blueprints of the profession (Thornley 2000). However, their growth in number has been accompanied by marked diversity, as illustrated by their "bewildering" breadth of job titles, skills, qualifications and other accreditation (Saks \& Allsop 2007, p165; Australian Nursing Federation 2009). Moreover, definitions of their role tend to focus on their position as adjuncts to registered or licensed professional groups, and do not describe what they actually do (e.g. Royal College of Nursing [RCN] 2006). This ambiguity has been amplified by wider policy changes including the creation of new extended, advanced practitioner roles in nursing and other allied health professions (Bach et al. 2008; Maier et al. 2016) and shifts towards integrated (multidisciplinary, multiagency) teams (WHO 2016), which have together fundamentally altered established professional and agency boundaries around the world.

The modern community mental health team for older people (CMHT) offers an interesting microcosm of these changes. CMHTs adhere to an internationally recognised service design, encompassing a mix of psychiatrists, mental health nurses, occupational therapists (OTs), psychologists, social and support workers (Wertheimer, 1997; Willis et al. 2009, Semrau et al. 2011) who provide specialist psychiatric care for people with severe and complex mental health problems in their own homes. In the UK, mental health nurses are numerically dominant, but teams' composition is changing rapidly: in 2009, 87 per cent of CMHTs for older adults contained support workers compared with 59 per cent five years beforehand (Wilberforce et al. 2013).

\section{Managing role boundaries and conflict in community mental health teams}

Multidisciplinary working inevitably creates new boundaries that challenge existing working patterns, and there has been considerable apprehension about the substitution of registered nurses with support workers in the UK and elsewhere (Duffield et al. 2014; Munn et al. 2013; RCN 2015). Boundaries can be both horizontal (between occupational groups of similar professional status) and vertical 
(between occupational groups of different professional status). However, whereas the vertical boundaries between doctors and nurses roles have been well-researched, studies of the boundaries between regulated practitioners and support workers are sparse, poorly executed, and largely confined to general hospital settings (Workman 1996, Jack et al. 2004, Sibbald et al. 2004, Spilsbury \& Meyer 2004, Wakefield et al. 2009).

There may be particular sensitivities in community psychiatric care. Support workers commonly work with clients with complex needs, requiring understanding and judgement relating to psychiatric risk and vulnerability (Warne \& McAndrew 2004, Wilberforce et al. 2015) and the locus of CMHT work in people's homes raises particular concerns about autonomous working and supervision (McCrae et al. 2008). Furthermore, despite many calls for more formalised standards, training and career development opportunities, evidence to support the form of such education is scarce. Indeed, some researchers have baulked at 'credentialism', arguing that the particular advantages of mental health support workers come from their position outside traditional workforce structures (Huxley et al. 2009, Manthorpe et al. 2010, Repper \& Carter 2011).

CMHTs thus offer fertile ground to explore support worker roles in an environment where: their remit is under-researched; registered practitioners (with direct responsibility for support workers) manage multiple challenges to traditional occupational and organisational boundaries; and the service setting presents a number of unique features hindering practice.

\section{THE STUDY}

\section{Aims}

The study formed part of a wider, mixed methods programme of research which explored the factors that make for the effective working of CMHTs for older people (reference removed). The research 
reported in this paper aimed to explore the nature of the support worker role in CMHTs so as to place this on a sounder empirical footing. There were four research questions:

1. What a the support worker's role in terms of its key activities and focus?

2. Are the boundaries between the roles of support workers and registered practitioners clear?

3. Are support workers supervised and supported appropriately?

4. Do support workers think their training and career development opportunities are adequate?

\section{Design}

A qualitative design using semi-structured interviews and thematic framework analysis was employed to obtain rich, subjective data describing, interpreting and contrasting CMHT members' views and experiences of the support worker role (Ritchie et al., 2014).

\section{Sample}

Participants were recruited from nine CMHTs for older people geographically spread across England. Teams were selected from a national survey of CMHTs and exhibited different levels of integration to meet the wider study's needs (reference removed). However, all provided specialist mental health support for older adults (65+) with a range of organic and functional disorders and contained multiple professional disciplines, including support workers. Potential interviewees (selected by researchers to ensure a spread of occupations) were identified from staff lists provided by team managers, and approached by researchers.

\section{Data collection}

A broad topic guide was developed to provide a structure for the interviews and ensure orientation to the research questions whilst still allowing other issues of importance to interviewees to emerge. 
Questions were tailored to reflect the specific interviewee's position in the team and focused on the individual's own roles and responsibilities and the difference between these and those of other team members. In particular, all professional staff were asked about the role of support workers, including how clear this was, the range of work they undertook and how they were supervised. These subjects were identified as areas in need of further research in the aforementioned survey (reference removed). The topic guide was reviewed after initial interviews, but was unchanged for subsequent fieldwork. Face-to-face interviews were undertaken by four researchers (MA, MW, RJ, ST), and were scheduled for one hour. Discussions were audio-recorded (with permission) and professionally-transcribed. Data collection was complete by summer 2011.

\section{Ethical considerations}

The study was granted ethical approval by an NHS Research Ethics committee (10/H0306/51). All participants received information about the research prior to agreeing to take part and gave written consent at the start of the interviews.

\section{Data analysis}

Thematic framework analysis was used to manage the interview transcripts and to identify themes within them, ensuring the interpretation was "heavily grounded in and supported by" the data (Ormston et al. 2003, p22). This approach aided the identification of patterns of meaning within the data through a rigorous process, moving from description to explanation. There were five stages: familiarisation; the use of charts to sort, index, review and summarise data extracts; the construction of a thematic framework; abstraction; and theory building. The data were initially coded by one researcher (MA) using ATLAS.ti software. Preliminary codes were informed by questions in the original topic guide (sorting and indexing). The coded data were then transferred to Excel spreadsheets (charts) for further analysis by four researchers, individually and together (MA, MW, 
SA, ST). This involved their reviewing the preliminary codes, developing categories and identifying new themes emerging from the data, as well as sharing and exploring the associations and links between them. Subsequent to the agreement of the final codes, categories and themes, further meetings were held to reflect on and interpret the data, leading to abstraction and theorising among the team as whole. Analysis paid particular attention to differences in the perspectives of registered practitioners and support workers.

\section{Rigour}

The interview data were audio recorded, professionally transcribed and collaboratively analysed by four researchers. In detail, one researcher read the transcripts and developed an initial coding frame which formed the basis for the identification of key themes by four researchers working first individually and then collectively. Discussion was used to challenge interpretations and reach a consensus of understanding. This thorough, transparent and systematic approach ensured the production of "well-founded and trustworthy evidence" (Ormston et al. 2014, p23).

\section{FINDINGS}

Table 1 describes both the interviewed sample and the broader membership of the nine CMHTs. The 42 interviewees represented seven staff groups and included five support workers. The sample comprised interviewees with varying experience in mental health (between two and 32 years) and in the CMHT (between one and 20 years). Interviewees also varied in grade in line with their role and experience. Using NHS Agenda for Change banding (DH 2004), support workers were employed on Bands 2 and 3; mental health nurses and occupational therapists Bands 5 and 6; team managers Band 7; and psychologists Band 8a. Equivalent data were not available for social workers who expressed other representations of grade, such as 'senior'. 


\section{[Table 1]}

\section{What is the support worker role?}

The 21 support workers in the participating teams had nine different job titles (three variants of 'support worker', occupational therapy assistant, nursing assistant, social work assistant, community health care assistant, health care assistant and support, time and recovery worker) and undertook a wide variety of activities, ranging from supporting hospital appointments to teaching relaxation skills. Table 2 lists the most commonly reported activities, organised into seven domains. Of these, monitoring was most frequently described, with multiple interviewees characterising support workers as "the eyes and ears" of registered practitioners. Most accounts of monitoring were broad, portraying it as serving a "maintenance" function, or, in one nurse's words, helping service users stay "on an even keel". However, others gave more detailed descriptions. For example, one OT noted that they would specifically ask support workers to "check out people's fridges, check that food's in date; that people are clean; they are dry".

\section{[Table 2]}

Some roles were reported to substitute for homecare, which one psychiatrist lamented being necessary due to long waits for social services support. For those needing help with household finance and paperwork, one social worker explained that she specified these were social care tasks when making a referral to the local authority, to free-up support worker time for therapeutic roles.

The different activities undertaken by support workers appeared to be linked to their individual skills and experiences. In two teams, for example, support workers with ward-based experience as healthcare assistants took blood pressures, assessed blood sugars and monitored medication side- 
effects, whilst an experienced support worker in another team delivered specialist training to homecare workers. Some interviewees also identified a profession-specific focus to support workers' roles. For example, one OT explained that where nursing assistants might refer clients to social services, 'her' support workers promoted personal independence at home:

\author{
"I guess some of the main differences between them is that our Technical Instructors \\ would be looking at building skills, of going in and looking at how much a person could \\ do domestic skills. What we want to do is to be able to get them to that optimum, what \\ they can do, before we have social services carers coming in...[who] tend to do \\ everything”. (Occupational Therapist, Team E)
}

Other support workers' roles were reported to have evolved over time, rather than being specified from the outset. For example, one support worker stated that her team thought she worked best with anxious patients, and that this role had "stuck":

\footnotetext{
"[Nurse] says: 'It's funny how your role has just happened'. The nurses have, sort of, thought: 'Right [support worker]'s good at this', and when they are out on their patch [nurse] says: "Oh, I think I've got one for you, I'll let you know”. So they've made their own assumptions of what I can do haven't they really, we haven't got it in black and white”. (Support worker, Team C)
}

For some staff, the functions or activities that support workers' undertook appeared less important than the relationships they established with service users. For example, one OT described such relationships as enabling service users to "hold things together", providing a solid platform for the provision of specialist support. Similarly, a psychiatrist described how the establishment of a positive rapport with a "reluctant" client led to their acceptance of home care, facilitating successful discharge from the CMHT. Comments from psychiatrists, nurses, OTs and support workers revealed a 
widespread belief that that support workers could more readily establish therapeutic relationships with service users than qualified practitioners, whose input could be interpreted as threatening:

"Our support workers offer a lot of reassurance, a lot of friendship ... their input can vary from being quite intense, to being quite light- hearted and, sort of, pop-in and a friendly face... There's lots of things that they'll divulge to the support workers that they wouldn't feel happy, necessarily, doing to a nurse or a consultant or a social worker, because it's the equal authority, it's the position type thing that the shutters go up... Support workers are ...more like a neighbour or a friend." (Community mental health nurse, Team B)

However, the interviewed support workers stressed that their relationships must not engender dependence:

\footnotetext{
“We don't just take over people's lives ... I am never going to create dependency...

You can never have them say: "What would I do without you?" (Support worker, Team I)
}

Whilst many team members used the word "appropriate" to describe an ideal relationship, in reality this was challenging to maintain. In one team a nurse was content to allow a support worker to undertake a "therapy of presence" that could involve "two, maybe even three hours... just spending time with them". However, as one OT cautioned: "feeling like a friend; it's hard to know where your professional boundaries are."

\section{Identifying and managing boundaries between staff}

When asked about the boundaries between registered practitioners' and support workers' roles and how clear these were, team members commonly spoke about the tasks support workers did not undertake. For example, there was widespread agreement that initial assessments, care planning and referrals to 
other services should be undertaken by registered practitioners in care coordination roles. In contrast, whilst members of some teams thought support workers could appropriately undertake therapeutic interventions, others disagreed. Hence one support worker eager to make best use of her long experience expressed frustration that she could not undertake limited CBT.

All interviewees agreed that support workers should not hold ultimate clinical responsibility for service users' care. Indeed, support workers typically referred to working "under" (rather than "alongside") qualified staff. Furthermore, although support workers were expected to monitor and report information on mental and physical health, the evaluation of this information was typically undertaken by registered practitioners:

\author{
“[Support worker] came back to me recently to say... there had been a change in \\ presentation for someone and the first thing [ I ] said back to her was: "Go back to the \\ family and get them to take her back to the GP'. And she hadn 't even thought of that \\ basic thing of taking her to the GP because a lot of people with dementia suffer from \\ infections..." (Occupational therapist, Team D)
}

Interviewees reflected on the way in which support workers' roles fitted with those of qualified staff. Three distinct functions were discerned. The first related to their undertaking additional tasks that would not previously have been done by qualified practitioners, such as supporting attendance at appointments and community groups. For example, one OT explained how the CMHT had previously had to persuade other community or voluntary services to get involved when service users needed accompanying to eyesight tests. Interestingly, support workers themselves were not always happy about undertaking such activities, particularly where they had little/no therapeutic value; one seeing this as being akin to a taxi service, and another as a 'happy shopper'.

A second function related to tasks registered professionals used to undertake, but no longer had time for. Such activities included monitoring and the delivery of therapeutic activities specified in care plans. 
Some registered practitioners lamented the loss of these roles (particularly the loss of client contact), but others appreciated the flexibility it gave them in managing their work:

"I think for that reason only, I think I'm glad that they are on board, and it takes some of the pressure [off] you because if you've got a couple of complex cases that are not well at the moment, I think sometimes you can still say: "Can you see these for me?", while I just concentrate on sort of focussing on these who I feel are going to need a bit more input." (Community mental health nurse, Team G)

Finally, there were examples of support workers undertaking duties registered staff considered inappropriate for them, but necessary in light of qualified staff shortages. Hence, one team manager talked about support workers undertaking memory assessments and gauging responses to newlyinitiated medication, whilst in three CMHTs support workers had undertaken de facto care coordination roles.

\section{Support and supervision}

In the majority of teams, support workers were managed by registered practitioners, who acted as care coordinators for the cases support workers saw. Supervision took many forms. Discussions about individual cases often took place on an ad-hoc basis as and when support workers felt issues warranted attention, but in one site, users' case notes were also countersigned by registered practitioners, providing additional opportunity for oversight. Over and above this, support workers and supervisors typically met formally every four-to-six weeks to consider particular cases in more detail.

In other instances, the team leader acted as the support worker's formal line manager, but ongoing casework was supervised by multiple registered practitioners. One support worker saw this as a good thing, saying each nurse she assisted had different expectations. There were also a number of 
examples of convoluted lines of supervision (formal and informal) resulting from geographical and organisational divisions. Hence, one support worker presented two separate lanyards, reflecting dual lines of accountability to the NHS and local authority, whilst another identified five authority figures giving her instruction, including the team manager, consultants and registered practitioners. Although there was clearly the potential for support workers to be pulled in different directions, the interviews provided little evidence of this, perhaps in part because each team held regular referral/review meetings, at which all team members, including support workers, were encouraged to express their views.

Nevertheless, there were instances where support workers felt inadequately supported. One support worker, for example, felt the consultant often forgot that she was not a qualified care coordinator, whilst another contrasted their responsibilities with those of hospital-based support workers:

\footnotetext{
"On the ward you are supervised by a qualified nurse. In the community you are out there on your own. Whether they say: "well you have got a CPN at the end of the phone, you have only go to ring, you know", there is not always somebody available. [Support worker, Team A]
}

Despite this, the support workers generally spoke positively about the autonomy and trust they were afforded, noting that although the broad content of their work was specified in individual care plans, within these confines they had ample scope to use their own judgement. Indeed, one social worker spoke of her initial surprise upon joining the team at the level of autonomy support workers had, contrasting this with the heavily prescribed role of home care workers. However, she felt this independence was warranted due to their extensive knowledge of mental health.

\section{Training and career structures}


The support workers provided evidence of both inconsistent opportunities for training and a varied appetite for skill acquisition and progression. To achieve career advancement, it was generally recognised that formal higher education towards full professional qualification was necessary. One support worker had completed a university course in anticipation of being accepted for registration on a nursing degree, only to find the enrolment criteria had changed. At the time of the interview, she reported being "stuck", because no other training would lead to improved pay. Another had begun a university foundation degree course, but dropped-out because of the heavy time implications for her home life. In contrast, a third explained that they were not interested in a qualified role "because it's more paperwork and I like to be hands-on".

Although short training courses, workshops and seminars were said to be available to support workers, there was no particular expectation that they should attend these. Moreover, it appeared that support workers struggled to find appropriate training. On the one hand, some generic mental health awareness and dementia courses had proved too simplistic, with one support worker saying "we could have taught them [the trainers] more... because when you've been involved [with] so many [real people], there's only so much you can learn". On the other hand, courses aimed at qualified staff were not necessarily appropriate either. One support worker explained that they did not want to know too much about medication without the underpinning knowledge, and felt their attending would be disrespectful to "those nurses that have done years of training", whilst another had attended similar training and found it hard to follow. However, a third felt strongly that such opportunities should be open to support workers:

"When there are certain trainings like cognitive behavioural therapies and they say "oh no, it's not for you, it's for professionals". Then I get hurt, and I get angry because it's almost suggesting that I am probably not capable of learning that, or perhaps within my role it's not really necessary, which is bumpf." [Support worker, Team D] 
Finally, although qualified practitioners and team managers were not explicitly asked their thoughts on training or career structures for support workers, they often spoke of support workers' lack of formal training for particular tasks and appeared to perceive 'on-the-job' experience as key to giving qualified practitioners confidence when delegating skilled tasks.

\section{DISCUSSION}

The steady but dramatic expansion of support worker numbers, both domestically and internationally, appears weakly founded in evidence. International studies of the link between grade-mix and patient outcomes are equivocal and stymied by methodological challenges (Buchan \& Dal Poz, 2006). Opinion, rhetoric and pragmatism may thus have achieved an upper-hand over empirical research in job design. In psychiatric care, the evidence-base is particularly sparse; the limited evidence on support worker roles in inpatient settings is inconclusive (e.g. Hanrahan \& Aiken 2008, Schneider et al. 2010), and even supportive authors have expressed concern over an 'ad-hoc' introduction of support workers without rigorous evaluation (Browne et al. 2013). Research on support work in community old age mental health care, where role specification appears particularly diverse, is at a premium. This new evidence from nine CMHTs employing 21 support workers provides valuable insight into their roles and boundaries.

Kessler and colleagues (2010) posit four public policy goals that may be met by expanding support worker numbers - 'relief', 'substitute', 'co-producer' and 'apprentice'. These align well with this study's findings. The first relates to their role in relieving qualified practitioners of routine, timeconsuming activities, acting as an 'aide'. International evidence regarding support workers undertaking of ancillary nursing tasks appears to convince even sceptical authors that a strictly complementary function is welcome given the global shortfall in nurses and escalating demands (Duffield et al. 2015). This paper presents numerous examples of this function as illustrated by the monitoring and 'maintenance' activities described above, whilst a similar role has been identified in 
the few previous studies of mental health support workers (Meek 1998, Huxley et al. 2005, McCrae et al. 2008).

However, whereas 'relief' is largely welcome, 'substitution', whereby support workers undertake core duties traditionally reserved for qualified staff, is more contentious. In common with research in acute hospitals (Spilsbury et al. 2011), this research found greatest agreement on what support workers should not do. Yet, despite this, several examples were identified of support workers undertaking activities beyond their perceived expertise (e.g. acting as de facto care coordinators, delivering therapeutic interventions) or, indeed, outside the CMHT remit (e.g. ongoing domiciliary care). This is not the first study to identify support worker role drift in psychiatric care. For example, Cowan and colleagues (2015) found similar examples in Australian inpatient settings. However, the combination of role drift with poor or absent supervision at crucial moments in care provision perhaps make the present study's findings more troubling, especially in community settings support where direct oversight is more challenging than on hospital wards.

The study revealed a general acceptance that support workers are able to establish more authentic and natural relationships with service users than qualified staff, echoing findings from earlier studies (Murray et al. 1995, MacRae et al. 2008, Meek 2008), especially for patients reluctant to engage with services. This identifies a clear 'co-production' function; that support workers contribute addedvalue, different to what could be achieved with an adequate supply of qualified staff. Parallels can be drawn with peer support/advocacy roles in working-age adult services in the UK, Australia and US, where the employment of workers with lived experience of mental health problems is reported to counter concerns that professional services are overly-medical; focus on the condition rather than the person; and are delivered 'to' rather than 'with' service users (Huxley et al. 2005, Lawn et al. 2008; Kemp \& Henderson 2012). Nevertheless, the interviews suggest that despite their 'authentic' appearance, these relationships can be used 'strategically' to identify needs and information that service users would be unwilling to share directly with qualified practitioners. More generally, these relationships were used to shift service users' acceptance of support so that other community services 
could engage with them. Though likely beneficial to service users' long-term interests, this raises the question as to whether service users are fully aware of registered practitioners asking support workers to visit them for these reasons. Operating somewhere "between friend and employee" (Manthorpe et al. 2010, p319), support workers challenge conventional boundaries.

Finally, Kessler et al (2010) suggest support workers improve the capacity of the workforce through an 'apprentice' function. The aforementioned widely-documented global shortfall in nursing skills, coupled with difficulties recruiting nurses to mental health and geriatric specialties, provides a compelling case to find new ways to meet the growing demands of people with dementia and other mental health problems in later life. However, the adequacy of support worker skills and training has long been questioned (McCrae et al, 2008) and the extent of variability in these is as an international problem spanning nursing specialties. Whilst previous research has tended to focus on causes rooted in care providers, supervisors and support workers themselves (Munn et al. 2013), the present research also highlights course quality and supply. Training was not always readily available, nor pitched at the right level: either failing to recognise the practical experience of many support workers; or assuming prior knowledge akin to qualified practitioners. In England, a new 'apprenticeship' route with an 'associate' grade has also been proposed (Health Education England, 2016). Whether these ambitions will be met with high quality education and training provision is, as yet, unknown.

\section{Limitations}

Although this research benefits from the perspectives of 42 practitioners from nine multidisciplinary community-oriented teams, its focus on CMHTs restricts the extent to which the interviewees' experiences might be considered representative of a wider range of services. Furthermore, despite interviewees being selected from teams containing 21 support workers, only five participants were support workers themselves. Richer data and more refined exploration (including comparison of support workers allied to particular disciplines) could be achieved by interviewing more support 
workers. Further, although the presented analysis allows some contrast between the views of support workers and other staff groups, it did not explore particular professional perspectives (e.g. views of social workers, nurses etc.) in any depth. Finally, it is recognised that the study lacked a service user voice, and that this gap in current knowledge needs to be addressed.

\section{CONCLUSION}

This research has a number of practice and policy implications for mental health nursing. Support workers were found to have a diverse remit, often 'negotiated' with their supervisors. At times, boundaries with registered nurses and other professionals were breached and supervision was not always commensurate with delegated responsibilities. Given widespread international tension about whether support workers act as substitutes for registered nurses, clear guidelines may be needed, especially in relation to older adults where complex mental health problems can interplay with physical illness and frailty. The study also found that support workers played a key role in facilitating engagement between service users and other community social care services, enabling longer-term support packages to be established. Given the challenges of engaging effectively with some older adults at risk of self-neglect, this role merits further research. Finally, the study found that training pathways for support workers were absent or perceived as blocked, and suggests that this may at least in part be due to a lack of appropriate training. In addition to setting clear expectations and standards for training, local and national work may be required to examine the adequacy and quality of supply. Unless barriers are addressed, hopes that support workers could advance to plug shortages at higher skill levels may falter. 


\section{REFERENCES}

Australian Nursing Federation. (2009). Balancing risk and safety for our community: Unlicensed health workers in the health and aged care systems. ANF, Canberra.

Bach, S., Kessler, I., \& Heron, P. (2008) Role redesign in a modernised NHS: the case of health care assistants. Human Resource Management Journal 18(2), 171-187.

Browne, G., Cashin, A., Graham, I \& Shaw, W. (2013). Addressing the mental health nurse shortage: Undergraduate nursing students working as assistants in nursing in inpatient mental health settings. International Journal of Nursing Practice 19 (5), 539-545.

Buchan, J., \& Dal Poz, M. R. (2002) Skill mix in the health care workforce: reviewing the evidence. Bulletin of the World Health Organization 80(7), 575-580.

Cowan, D., Frame, N., Brunero, S., Lamont, S., \& Joyce, M. (2015). Assistants in nursing perceptions of their social place within mental health-care settings. International Journal of Mental Health Nursing, 24(5), 375-447.

Department of Health. (2007) Support, Time and Recovery (STR) Workers: Learning from the national implementation programme: Final Handbook. DH, London.

Department of Health. (2004) Agenda for Change final agreement. DH, London.

Dubois, C-A., \& Singh, D. (2009). From staff-mix to skill-mix and beyond: towards a systemic approach to health workforce management. Human Resources for Health 7(87), 1-19.

Duffield, C., Twigg, D., Pugh, J., Evans, G., Dimitrelis, S., \& Roche, M. (2014).The use of unregulated staff: Time for regulation? Policy, Politics and Nursing Practice 15 (1-2), 42-48.

Frenk, J., Chen, L., Bhutta, Z. A., Cohen, J., Crisp, N., Evans, T., Fineberg, H., Garcia, P., Ke, Y., Kelley, P., Kistnasamy, B., Meleis, A., Naylor, D., Pablos-Mendez, A., Reddy, S., Scrimshaw, S., Sepulveda, J., Serwadda, D., \& Zurayk, H. (2010) Health professionals for a new century: transforming education to strengthen health systems in an interdependent world. Lancet 376(9756), 1923-58.

Fulton, B. D., Scheffler, R. M., Sparkes, S. P., Auh, E. Y., Vujicic, M., \& Soucat, A. (2011). Health workforce skill mix and task shifting in low income countries: a review of recent evidence. Human Resources for Health 9(1), 1-11.

Hanrahan, NP., \& Aiken, L. (2008). Psychiatric nurse reports on the quality of psychiatric care in 
general hospitals. Quality Management of Health Care, 17(3), 210-217.

Health Education England. (2016) Building capacity to care and capability to treat - a new team member for health and social care: Consultation. HEE, London.

Health and Social Care Information Centre. (2016) NHS Workforce Statistics: November 2015 (Provisional Statistics). Retrieved from https://www.gov.uk/government/statistics/nhsworkforce-statistics-november-2015-provisional-statistics.

Huxley, P., Evans, S., Beresford, P., Davidson, B., \& King, S. (2009). The principles and provisions of relationships findings from an evaluation of support, time and recovery workers in mental health services in England. Journal of Social Work 9(1), 99-117.

Huxley, P., King, S., Evans, S., Davidson, B. \& Beresford, P. (2005) 'No Recovery without Time and Support' (or 'More than Bowling Together'). Evaluation of the introduction of Support, Time \& Recovery Workers in three pilot sites. King's College London, London.

International Council of Nurses. (2000). Assistive or support nursing personnel. ICN, Geneva.

Jack, B., Brown, J., \& Chapman, T. (2004) Ward managers' perceptions of the role of healthcare assistants. British Journal of Nursing 13(5), 270-5.

Kessler, I., Heron, P., Dopson, S., Magee, H., Swain, D. \& Askham, J. (2010) The Nature and Consequences of Support Workers in a Hospital Setting: Final Report. NIHR Service Delivery and Organisation, NIHR, London.

Kemp, V \& Henderson, AR. (2012). Challenges faced by mental health peer support workers: Peer support from the peer supporter's point of view. Psychiatric Rehabilitation Journal, 35(4), 337340.

Lawn, S., Smith, A. \& Hunter, K. (2008). Mental health peer support for hospital avoidance and early discharge: An Australian example of consumer driven and operated service. Journal of Mental Health, 17(5), 498-508.

Maier, C., Barnes, H., Aiken, L., \& Busse, R. (2016). Descriptive, cross-country analysis of the nurse pratitioner workforce in sizx countries: Size, growth, physician substitution potential. BMJ Open 6, 1-11.

Manthorpe, J., Martineau, S., Moriarty, J., Hussein, S., \& Stevens, M. (2010) Support workers in social care in England: a scoping study. Health \& Social Care in the Community 18(3), 316-324.

McCrae, N., Banerjee, S., Murray, J., Prior, S., \& Silverman, A. M. (2008) An extra pair of hands? A 
case study of the introduction of support workers in community mental health teams for older adults. Journal of Nursing Management 16(6), 734-43.

Meek, I. (1998) Evaluation of the role of the health care assistant within a community mental health intensive care team. Journal of Nursing Management 6(1), 11-19.

Munn, Z., Tufanaru, C. \& Aromataris, E. (2013). Recognition of the health assistant as a delegated clinical role and their inclusion in models of care: A systematic review and meta-synthesis of qualitative evidence. International Journal of Evidence-Based Healthcare, 11(1), 3-19.

Murray, A., Shepherd, G., Oynett, S. \& Muijen, M.(1997) More Than a Friend: The Role of Support Workers in Community Mental Health Services. The Sainsbury Centre for Mental Health, London.

Ormston, R., Spencer, L., Barnard, M. \& Snape, D. (2013) The foundations of qualitative research. In Ritchie, J., Lewis, J., Nicholls, C.M. and Ormston, R. (eds.) (2013) Qualitative research practice: A guide for social science students and researchers. Sage, Thousand Oaks

Repper, J., \& Carter, T. (2011) A review of the literature on peer support in mental health services. Journal of Mental Health 20(4), 392-411.

Ritchie, J., Lewis, J., Nicholls, C.M. and Ormston, R. (eds.) (2013) Qualitative research practice: A guide for social science students and researchers. Sage, Thousand Oaks.

Royal College of Nursing. (2015). Registered Nurses and Health Care Support Workers: A summary of RCN policy positions. RCN, London

Royal College of Nursing. (2006). Supervision, accountability and delegation of activities to support workers: A guide for registered practitioners and support workers. RCN, London.

Saks, M., \& Allsop, J. (2007). Social policy, professional regulation and health support work in the United Kingdom. Social Policy and Society 6(2), 165-177.

Schneider, J., Scales, K., Bailey, S., \& Lloyd, J. (2010). Challenging care: The role and experience of Health Care Assistants in dementia wards. Report for the NIHR Service Delivery and Organisation programme.

Sibbald, B., Shen, J., \& McBride, A. (2004). Changing the skill-mix of the health care workforce. Journal of Health Services Research \& Policy 9(Suppl 1), 28-38.

Semrau, M., Barley, E., Law, A., \& Thornicroft, G. (2011). Lessons learned in developing community mental health care in Europe. World Psychiatry 10(3), 217-225. 
Spilsbury, K., \& Meyer, J. (2004) Use, misuse and non-use of health care assistants: understanding the work of health care assistants in a hospital setting. Journal of Nursing Management 12(6), 411-8.

Spilsbury, K., Adamson, J., Atkin, K., Bloor, K., Carr-Hill, R., McCaughan, D., McKenna, H., \& Wakefield, A. (2011). Challenges and opportunities associated with the introduction of assistant practitioners supporting the work of registered nurses in NHS acute hospital trusts in England. Journal of Health Services Research \& Policy, 16(supp 1), 50-56.

Thornley, C. (2000) A question of competence? Re-evaluating the roles of the nursing auxiliary and health care assistant in the NHS. Journal of Clinical Nursing 9(3), 451-458.

Wakefield, A., Spilsbury, K., Atkin, K., McKenna, H., Borglin, G., \& Stuttard, L. (2009). Assistant or substitute: exploring the fit between national policy vision and local practice realities of assistant practitioner job descriptions. Health Policy 90(2-3), 286-95.

Warne, T., \& McAndrew, S. (2004) The mental health assistant practitioner: an oxymoron? Journal of Psychiatric and Mental Health Nursing 11(2), 179-184.

Wertheimer, J. (1997). Psychiatry of the elderly: A consensus statement. International Journal of Geriatric Psychiatry 12(4), 432-435.

Wilberforce, M., Tucker, S., Abendstern, M., Brand, C., Giebel, C. M., \& Challis, D. (2013) Membership and management: structures of inter-professional working in community mental health teams for older people in England. International Psychogeriatrics 25(9), 1485-92.

Wilberforce, M., Tucker, S., Brand, C., Abendstern, M., Jasper, R., Stewart, K., \& Challis, D. (2015). Community mental health teams for older people: variations in case mix and service receipt (II). International Journal of Geriatric Psychiatry 30(6), 605-613.

Willis, E., Reynolds, L. \& Keleher, H. (2009). Understanding the Australian health care system. Chatswood NSW, Elsevier Australia.

Workman, B. A. (1996). An investigation into how the health care assistants perceive their role as "support workers" to the qualified staff. Journal of Advanced Nursing 23(3), 612-9.

World Health Organization. (2016). Framework on integrated, people-centred health services: Report by the Secretariat. WHO, Geneva. Available at www.who.int/servicedeliverysafety/areas/people-centred-care/en/ [accessed 18 November 2016]

World Health Organization. (2007). Counting health workers: Definitions, data, methods and global results. WHO, Geneva. 
